\section{Вангородская Светлана Анатольевна}

кандидат социологических наук, доцент кафедры социальных технологий и государственной службы

Белгородского государственного национального исследовательского университета

\section{Начкебия Майя Севериановна}

старший преподаватель

кафедры социальных технологий

и государственной службы

Белгородского государственного национального исследовательского университета

\section{ПРИМЕНЕНИЕ \\ МОДЕЛИРОВАНИЯ В ИЗУЧЕНИИ \\ САМОСОХРАНИТЕЛЬНОГО ПОВЕДЕНИЯ: ОСОБЕННОСТИ И ПЕРСПЕКТИВЫ}

\section{Аннотация:}

В статье рассматриваются теоретические ас пекты моделирования самосохранительного поведения. Разработка социологических инструментов моделирования представлена как одно из перспективных направлений анализа социально-экономических, политических и социокультурных процессов. Выделены основные этапы моделирования, а также сложности, возникающие в процессе построения моделей самосохранительного поведения. Отмечено перспективное направление создания моделей самосохранительного поведе ния, которое заключается в использовании агентного (агент-ориентированного) метода имитационного моделирования. Указано, что при построении агентных имитационных моделей самосохранительного поведения целесообразно использовать как статические параметры, значения которых индивидуальны и неизменны в процессе построения моделей для каждого агента, так и динамические переменные, значения которых могут изменяться в процессе моделирования. Сделан вывод о преимуществах использования агентного метода имитационного моделирования 6 изучении теоретических и эмпирических аспектов феномена самосохранительного поведения.

Ключевые слова:

модель, моделирование социальных процессов, самосохранительное поведение, поведение в отношении здоровья, модели самосохранительного поведения, этапы моделирования, параметры модели, имитационное моделирование, агент-ориентированное моделирование.
Vangorodskaya Svetlana Anatolyevna

PhD in Social Science, Associate Professor, Social Technologies and Public Service Department Belgorod State National Research University

Nachkebiya Maya Severianovna

Senior Lecturer, Social Technologies and Public Service Department, Belgorod State National Research University

\section{APPLICATION OF MODELING IN THE STUDY OF SELF-PRESERVATION BEHAVIOR: FEATURES AND PROSPECTS}

Summary:

The paper deals with the theoretical aspects of selfpreservation behavior modeling. The development of sociological modeling tools is presented as one of the promising areas of analysis of socio-economic, political and socio-cultural processes. The main stages of modeling are highlighted, as well as the difficulties that arise in the process of building models of self-preservation behavior. The use of an agent-based (agent-oriented) method of simulation is noted as one of the promising directions for creating models of self-preserving behavior. It is also noted that when constructing agent-based simulation models of self-preserving behavior, it is advisable to use both static parameters, the values of which are individual and unchanged in the process of building models for each agent, and dynamic variables, the values of which can change during the modeling process. The conclusion is made about the prospects of using the agent based method of simulation in the study of theoretical and empirical aspects of the phenomenon of self preservation behavior.

Keywords: model, social process modeling, self-preservation behavior, health behavior, self-preservation behavior models, modeling stages, model parameters, simulation modeling, agent-oriented modeling.

Познавательные возможности моделирования как метода изучения социальной действительности стали предметом пристального внимания отечественных и зарубежных исследователей со второй половины XX века. Именно в этот период в нашей стране были опубликованы фундаментальные работы Б.А. Глинского, Б.С. Грязнова, Б.С. Дынина, А.А. Зиновьева, Н.М. Мамедова, Е.П. Никитина, И.Б. Новика, И.И. Ревзина, А.И. Уёмова, И.Т. Фролова, В.А. Штоффа, в которых рассматривались гносеологические основы и методологические принципы моделирования социальных процессов. 
Получив широкое распространение во многих отраслях научного знания, моделирование позволило расширить ассортимент исследовательских методов в изучении сложных явлений и феноменов социальной действительности. Как справедливо отметил О.Ф. Шабров, «сама социальная жизнь как в России, так и во всем мире усложнилась настолько, что адекватная оценка происходящего стала невозможной без применения специальным образом фрормализованных процедур» [1, с. 100], одной из которых и стало моделирование.

К числу наиболее существенных преимуществ моделирования можно отнести возможность разработки прогнозных сценариев трансформации того или иного явления (феномена) с тем, чтобы просчитать и по возможности минимизировать те негативные последствия, которые могут сопровождать этот процесс в различные периоды времени. В этом плане моделирование выступает в качестве дополнительного инструмента прогнозирования социальной реальности, дополняя такие признанные в науке методы, как метод экспертной оценки, регрессионный анализ, метод экстраполяции, тренд-анализ и др.

Сложность моделирования социальных процессов заключается в том, что, с одной стороны, сами эти процессы относятся к числу трудно формализуемых объектов, а с другой - навыков в построении моделей у социологов в большинстве случае хватает на создание схем или моделей, которые носят скорее общетеоретический характер. Безусловно, этот комплекс проблем характерен и для такого сложного социального феномена, как самосохранительное поведение, определяемое нами как «сознательная деятельность индивидов, направленная на поддержание оптимальных параметров биологического, психологического и социального здоровья и минимизацию субъективно осознаваемых рисков» [2].

Изучение теоретико-методологических аспектов моделирования социальных и социокультурных процессов, изложенных в исследованиях Ю.И. Бродского, Б.А. Глинского, В.В. Добровой, И.Д. Зайцева, З.М. Мамаевой, И.Е. Москалева, В.Я. Райцина, Ю.М. Плотинского, И.А. Торгунова, О.Ф. Шаброва, В.А. Шведовского и др., позволяет представить процесс моделирования самосохранительного поведения в виде совокупности последовательных этапов, к числу которых можно отнести:

1. Определение проблемной области моделирования самосохранительного поведения и выбор методологических подходов к исследованию данного социального феномена. На данном этапе необходимо учитывать тот факт, что построенная на основе той или иной теории модель может выступать в качестве подтверждения или опровержения данной теории, а также «указывать возможные пути развития теории и дополнительные области ее применения» [3, с. 82].

2. Формулировка основных целей и задач исследования феномена самосохранительного поведения посредством создания соответствующих моделей.

3. Выдвижение рабочих гипотез (предположений о переменных, влияющих на развитие моделируемого феномена, о возможных вариантах динамики развития объекта моделирования и т. д.).

4. Определение входных и выходных параметров модели (основных свойств (качеств, элементов) самосохранительного поведения), список исходных данных, критерии завершенности будущего исследования. На данном этапе решение о том, какие элементы найдут отражение в модели, а что останется за ее рамками, находится в прямой зависимости от компетенции исследователя, который перед принятием решения должен взвесить и проанализировать как совокупность характеристик системы, так и свои аналитические способности по интерпретации полученных посредством моделирования данных.

5. Структурирование проблемной области, т. е., выделение основных внутренних и внешних фракторов, влияющих на формирование самосохранительного поведения, определение характера и закономерностей их взаимосвязи. При этом необходимо принимать во внимание тот факт, что несмотря на достаточную изученность факторов самосохранительного поведения, их перечень может быть расширен уже в процессе построения моделей.

6. Построение концептуальной (содержательной) модели самосохранительного поведения, позволяющей определить общий причинно-следственный характер взаимосвязи между факторами. При создании моделей необходимо учитывать, что большая часть системообразующих элементов самосохранительного поведения получена путем теоретического анализа, данных эмпирических исследований, а также путем опроса экспертов. Это предполагает некую субъективность оценок (особенно в последнем случае), а также существенную долю качественных данных, требующих дополнительной трансформации для использования в рамках моделирования.

7. Формализация предметной области, т. е. выбор модели, призванной наиболее адекватно отобразить существенные свойства исследуемого феномена. Здесь важно принимать во внимание тот фракт, что самосохранительное поведение является одним их элементов многосферной системы социального воспроизводства, и при выборе модели необходимо помнить о 
необходимости обеспечения корреляции данных, полученных в ходе моделирования с другими данными и иными моделями.

8. Запуск модели и анализ результатов посредством проведения так называемых модельных экспериментов (нацеленных на специальное изменение условий функционирования модели с целью сбора определенной информации о ее поведении). В этом плане большими эвристическими возможностями обладает имитационное социальное моделирование (social simulation), выступающее удобным инструментом экспериментального проигрывания множества возможных сценариев типа «что-если» на основе неполной информации и в условиях динамичного изменения параметров объекта моделирования и окружающей среды.

9. Практическая проверка результатов (в том числе посредством проведения экспертных опросов), их использование для построения обобщающей теории самосохранительного поведения и последующей разработки рекомендаций по фрормированию оптимальных моделей самосохранительного поведения.

10. Разработка сценарных прогнозов изменения моделей самосохранительного поведения с обоснованием выгод и издержек участников моделируемых событий. И в этом плане моделирование, обеспечивающее «сжатие временных параметров» [4, с. 298] может оказать неоценимую услугу.

Построение моделей самосохранительного поведения (как и любого другого столь же сложного социального феномена) может быть сопряжено с определенными трудностями, обусловленными необходимостью получения точной информации о моделируемых отношениях, однозначного ее толкования и сужения до минимального объема, достаточного для осуществления моделирования. Исходя из этого, при построении моделей самосохранительного поведения возможны (и даже целесообразны) некоторые упрощающие допущения: учет влияния только основных экономических, социальных и этнокультурных факторов; бинарность отдельных субъективных характеристик (позволяющих в качестве вариантов выбора учитывать только да/нет, за/против); игнорирование некоторых характеристик (как объективных, так и субъективных), имеющих незначительный вес в формировании, поддержании и изменении соответствующих моделей самосохранительного поведения. Вместе с тем даже наличие такого упрощенного варианта моделирования способно, на наш взгляд, предоставить достаточно полную информацию о моделях самосохранительного поведения в современном российском обществе.

Одним из перспективных направлений построения моделей самосохранительного поведения может стать использование агентного (агент-ориентированного) метода имитационного моделирования, в качестве преимуществ которого отмечают его способность демонстрировать «как на основе совокупности индивидуальных решений рождается коллективное поведение» [5, с. 115] и который в последнее время все чаще используется в процессе моделирования экономических, политических и социокультурных процессов [6].

В качестве примера применения агент-ориентированного моделирования к исследованию демографических процессов можно привести модель «Россия», разработанную сотрудниками ЦЭМИ РАН для изучения репродуктивных стратегий поведения населения России [7], а также модель внутригородской миграции, авторами которой стали американские исследователи S. Sun, S.M. Manson [8].

Особенность использования агент-ориентированного моделирования применительно к феномену самосохранительного поведения заключается в том, что оно, не претендуя на создание целостной картины, позволяет в то же время подойти к анализу самосохранительного поведения населения любой территории, как к сумме действий множества агентов (от нескольких десятков до нескольких миллионов), обладающих различными самосохранительными установками, мотивами и стратегиями поведения, но живущими в общей среде, и создающими в конечном счете единое здоровьесберегающее пространство.

При построении агентных имитационных моделей самосохранительного поведения целесообразно использовать как статические параметры, значения которых индивидуальны и неизменны в процессе построения моделей для каждого агента (состояние экологии в месте проживания; гендерные, этнокультурные и иные особенности отношения к здоровью и пр.), так и динамические переменные, значения которых могут изменяться в процессе моделирования (экономический и социальный статус, возраст, состояние здоровья, самосохранительные установки, мотивы самосохранительного поведения, локус контроля в отношении своего здоровья и т. д.). Кроме того, важно учитывать и специфику психоэмоционального состояния агентов, складывающегося под влиянием внешних и внутренних фракторов и предопределяющего отношение к своему здоровью в единицу времени. 
Используя агент-ориентированное моделирование для изучения такого сложного феномена, как самосохранительное поведение, необходимо иметь в виду, что этот метод требует достаточно скрупулезного и ответственного подхода к постановке исследовательских целей и задач, а также отбору переменных, используемых для построения агентной модели. В противном случае, по справедливому замечанию Э.А. Лебедюк, ««мусорные» данные на входе дадут такой же результат и на выходе» [9, с. 160].

Агент-ориентированные модели самосохранительного поведения способны, с одной стороны, отразить достаточно сложную динамику процессов, детерминирующих отношение населения страны (региона) к своему здоровью, а с другой - определить (выявить) элементы различной степени стабильности с тем, чтобы спрогнозировать возможность воздействия на них на индивидуальном и социальном уровнях. Вместе с тем необходимо учитывать тот факт, что, позволяя решать задачи высокой степени сложности, агентное моделирование в то же время не является универсальным методом исследования и должно использоваться только в совокупности с другими инструментами для изучения особенностей и закономерностей самосохранительного поведения.

Таким образом, построение моделей самосохранительного поведения (в том числе посредством агент-ориентированного моделирования) может стать одним из перспективных инструментов изучения данного социального феномена, призванных не только систематизировать накопленные в этой области знания, но и получить количественную оценку факторов, детерминирующих демографическое поведение, позволяющих на их основе спрогнозировать возможные сценарии развития моделей самосохранительного поведения в современном российском обществе.

\section{Ссылки:}

1. Шабров О.Ф. Системный подход и компьютерное моделирование в политологическом исследовании // Общественные науки и современность. 1996. № 2. С. 100-110.

2. Вангородская С.А. Самосохранительное поведение: проблема содержания понятия в отечественной социологии // Среднерусский вестник общественных наук. 2017. Т. 12. № 4. С. 20-29. 10.22394/2071-2367-2017-12-4-20-29.

3. Stewart A.H. Graphic Representation of Models in Linguistic Theory. Bloomington, 1976. 195 p.

4. Глазунов Н. Г. Моделирование социальных процессов: проблемы теории и практики // Вектор науки ТГУ. 2011. № 1 (15). C. 297-301.

5. Евсеев Е.А. Ефимова Е.Д. Имитационная модель избирательной кампании // Проблемы управления в социальных системах. 2015. № 12. С. 114-129. 10.17223/2077-6160/12/8.

6. См.: Шабров О.Ф. Указ. соч. ; Евсеев Е.А. Ефимова Е.Д. Указ. соч. ; Макаров В.Л. Общее описание демографической модели «Россия» [Электронный ресурс] / В.Л. Макаров, Е.Д. Сушко, A.P. Бахтизин. URL: http://abm.center/publications/?ID=278 (дата обращения: 12.04.2020) ; Sun S., Manson S.M. Simple Agents, Emergent City: Agent-Based Modeling of Intraurban Migration // Computational Approaches for Urban Environments. Berlin, 2015. P. 123-147 ; Лебедюк Э.А. Агентное моделирование: состояние и перспективы // Вестник РЭУ им. Г.В. Плеханова. 2017. № 6 (96). С. 155-162 ; Маковеев В.Н. Применение агент-ориентированных моделей в анализе и прогнозировании социально-экономического развития территорий // Экономические и социальные перемены: факты, тенденции, прогноз. 2016. № 5 (47). С. 272-289. 10.15838/esc/2016.5.47.15 ; Чекмарева Е.А. Обзор российского и зарубежного опыта агент-ориентированного моделирования сложных социально-экономических систем мезоуровня // Экономические и социальные перемены: фракты, тенденции, прогноз. 2016. № 2 (44). С. 225-246. 10.15838/esc/2016.2.44.14 ; Швецов А.Н., Дианов С.В. Методика разработки агент-ориентированных моделей сложных систем // Вестник Череповецкого государственного университета. 2019. № 1. С. 48-58. 10.23859/1994-0637-2019-1-88-5.

7. Макаров В.Л. Указ. соч.

8. Sun S., Manson S.M. Op. cit.

9. Лебедюк Э.А. Указ. соч. С. 160 